\title{
Specific Host-Responsive Associations Between Medicago truncatula Accessions and Sinorhizobium Strains
}

\begin{abstract}
Théophile Kazmierczak, ${ }^{1}$ Marianna Nagymihály, ${ }^{2,3}$ Florian Lamouche, ${ }^{2}$ Quentin Barrière, ${ }^{2}$ Ibtissem Guefrachi, ${ }^{2}$ Benoit Alunni, ${ }^{2}$ Mouna Ouadghiri, ${ }^{4}$ Jamal Ibijbijen, ${ }^{5}$ Éva Kondorosi, ${ }^{2,3}$ Peter Mergaert, ${ }^{2}$ and Véronique Gruber ${ }^{1}$
\end{abstract}

${ }^{1}$ Institute of Plant Sciences Paris Saclay IPS2, CNRS, INRA, Université Paris-Sud, Université Evry, Université Paris-Saclay, Bâtiment 630, 91405 Orsay, France. Institute of Plant Sciences Paris-Saclay IPS2, Université Paris Diderot, Sorbonne Paris-Cité, Bâtiment 630, 91405, Orsay, France; ${ }^{2}$ Institute for Integrative Biology of the Cell, UMR 9198, CNRS/Université Paris-Sud/CEA, 91198, Gif-sur-Yvette, France; ${ }^{3}$ Institute of Biochemistry, Biological Research Centre, Hungarian Academy of Sciences, 6726 Szeged, Hungary; ${ }^{4}$ Collections Coordonnées Marocaines de Microorganismes et Laboratoire de Microbiologie et Biologie Moléculaire, Centre National pour la Recherche Scientifique et Technique, Rabat, Maroc; and ${ }^{5}$ Faculté des Sciences, Université Moulay Ismail, Meknès, Maroc, Faculté des Sciences, Université Moulay Ismail, BP 11201 Zitoune, Meknès, Maroc

Accepted 7 March 2017.

\begin{abstract}
Legume plants interact with rhizobia to form nitrogen-fixing root nodules. Legume-rhizobium interactions are specific and only compatible rhizobia and plant species will lead to nodule formation. Even within compatible interactions, the genotype of both the plant and the bacterial symbiont will impact on the efficiency of nodule functioning and nitrogen-fixation activity. The model legume Medicago truncatula forms nodules with several species of the Sinorhizobium genus. However, the efficiency of these bacterial strains is highly variable. In this study, we compared the symbiotic efficiency of Sinorhizobium meliloti strains Sm1021, 102F34, and FSM-MA, and Sinorhizobium medicae strain WSM419 on the two widely used $M$. truncatula accessions A17 and R108. The efficiency of the interactions was determined by multiple parameters. We found a high effectiveness of the FSM-MA strain with both $M$. truncatula accessions. In contrast, specific highly efficient interactions were obtained for the A17-WSM419 and R108-102F34 combinations. Remarkably, the widely used Sm1021 strain performed weakly on both hosts. We showed that Sm1021 efficiently induced nodule organogenesis but cannot fully activate the differentiation of the symbiotic nodule cells, explaining its weaker performance. These results will be informative for the selection of appropriate rhizobium strains in functional studies on symbiosis using these $M$. truncatula accessions, particularly for research focusing on late stages of the nodulation process.
\end{abstract}

Soil bacteria called rhizobia interact with the root system of legume plants in a coordinated developmental program to form

T. Kazmierczak and M. Nagymihály contributed equally to this work.

Current address for I. Guefrachi: Université de Pau et des Pays de l'Adour, Pau, France.

Corresponding authors: P. Mergaert; E-mail: peter.mergaert@i2bc.paris-saclay. fr and V. Gruber; E-mail: veronique.gruber@ips2.universite-paris-saclay.fr

*The $\boldsymbol{e}$-Xtra logo stands for "electronic extra" and indicates that six supplementary figures are published online.

(c) 2017 The American Phytopathological Society symbiotic root nodules. Within the cells of these nodules, nitrogenfixing rhizobia provide the host plant with fixed nitrogen. The rhizobium-legume symbiosis attracts considerable interest because of its impact on the global nitrogen cycle and its potential biotechnological application for nitrogen nutrition in agriculture (Oldroyd and Dixon 2014). Medicago truncatula is a legume species that has been intensively studied because of its attractive features as a laboratory model system (Cheng et al. 2014; Rose 2008).

$M$. truncatula forms indeterminate nodules characterized by distinct developmental zones, organized from the youngest part at the nodule tip to the oldest root proximal region (Ferguson et al. 2010; Kondorosi et al. 2013; Lotocka et al. 2012; Oldroyd and Downie 2008). A persistent apical meristem (zone I) is composed of dividing cells and is responsible for the indeterminate growth of the nodule. In the infection/differentiation zone (zone II) postmeristematic cells are invaded by rhizobia and the infected nodule cells differentiate along with their intracellular rhizobia. In the nitrogen-fixation zone (zone III), the differentiated bacteria, bacteroids, and their host symbiotic nodule cells are mature and fix atmospheric nitrogen. Aging nodule cells constitute the senescence zone (zone IV) in which first the bacteroids and, then, the host cells degenerate.

The differentiation of the nodule cells in zone II is marked by a dramatic increase in their cell size, which is driven by several endoreduplication (ER) cycles leading to mature symbiotic nodule cells with a nuclear DNA content up to $64 \mathrm{C}$ (C is the haploid DNA content) and a size, about $50 \mu \mathrm{m}$ in diameter, that is up to 80-fold larger than their progenitor cells in the meristem (Vinardell et al. 2003). The polyploidy of the symbiotic nodule cells is essential to their function, since knockdown of CCS52A, a regulator of the ER step, leads to nonfunctional nodules (Vinardell et al. 2003). Moreover, the formation of polyploid nodule cells is correlated with the activation of expression of hundreds of nodule-specific genes (Maunoury et al. 2010; Roux et al. 2014).

The rhizobia that are released into the cells of zone II also differentiate concomitantly with their host cells (Mergaert et al. 2006; Vasse et al. 1990). The released rhizobia first proliferate, partially filling the infected cell. However, their division is rapidly inhibited. The bacteria, nevertheless, continue to grow by cell enlargement driven by polyploidization, not unlike the 
growth of their host cells. At the end of the process, the bacteria entirely fill the host cell and are terminally differentiated into large polyploid nitrogen-fixing bacteroids. The process of terminal differentiation of bacteroids is mediated by host cellproduced peptides known as nodule-specific cysteine-rich (NCR) peptides (Alunni and Gourion 2016; Penterman et al. 2014; Van de Velde et al. 2010).

The M. truncatula subsp. tricycla R108 (Hoffmann et al. 1997; Yoder et al. 2013) and M. truncatula Jemalong A17 (Young et al. 2011) accessions are particularly widely used for research on the legume-rhizobium symbiosis because of their superior transformation capacity and the availability of extensive transcriptome data, genome sequence, and large-scale mutant collections (Cheng et al. 2014; Young et al. 2011; the Medicago truncatula Hapmap Project database). These plants establish symbiosis with several species of the Sinorhizobium genus, including $S$. meliloti and $S$. medicae strains, although the symbiotic efficiency (i.e., the plant benefit derived from the symbiosis) of these strains is variable (Laguerre et al. 2012; Larrainzar et al. 2014; Liu et al. 2014). S. meliloti is among the most characterized and first sequenced rhizobia (Galibert et al. 2001) and, therefore, the reference strain Sm1021, its sister
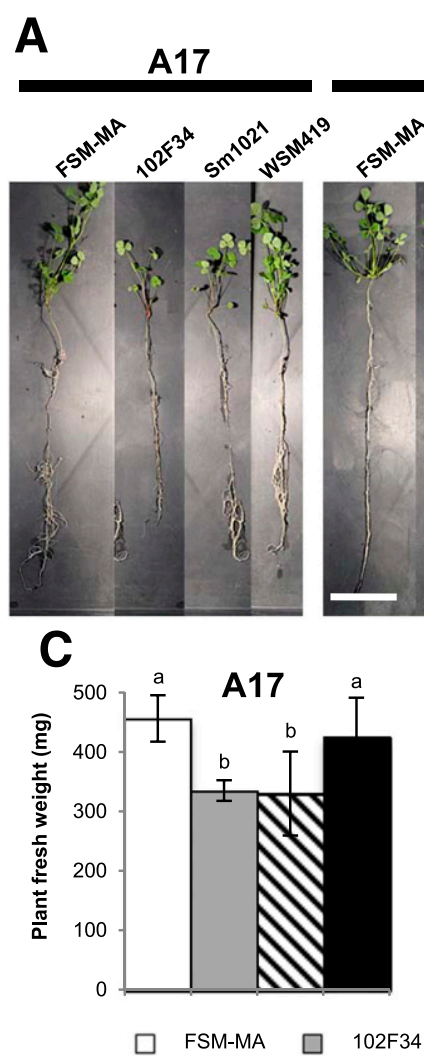

R108

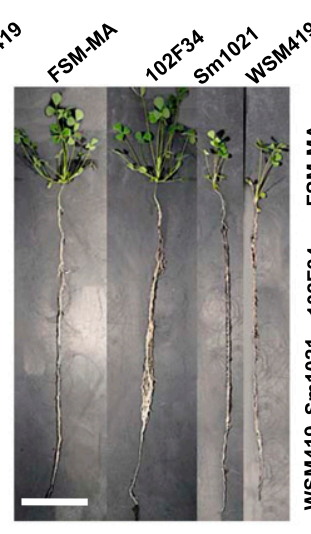

D

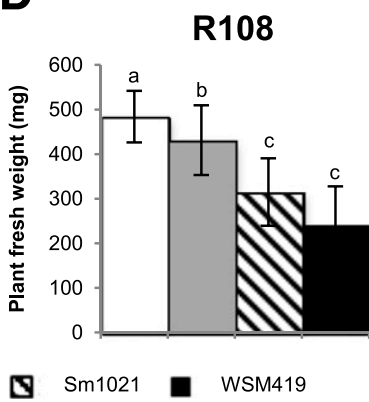

Fig. 1. Plant growth of Medicago truncatula A17 and R108 inoculated with different Sinorhizobium strains. A, Phenotypes of M. truncatula A17 and R108 at 5 weeks postinoculation (wpi) with bacterial strains FSM-MA, 102F34, Sm1021, and WSM419. All the plants were photographed at the same scale. The scale bar represents $10 \mathrm{~cm}$. B, Leaf phenotypes of $M$. truncatula A17 and R108 at 5 wpi with the different bacterial strains FSMMA, 102F34, Sm1021, and WSM419. First foliar rank leaves were pictured. Scale bars represent $0.5 \mathrm{~cm}$. C, Plant biomass production (fresh weight) of Medicago truncatula A17 at 5 wpi with bacterial strains FSMMA, 102F34, Sm1021, and WSM419. Values represent the mean \pm standard error $(n=10)$. Letters indicate statistical differences between groups $(P<$ 0.05 , Kruskal-Wallis test). D, Plant biomass production (fresh weight) of M. truncatula R108 at 5 wpi with the bacterial strains FSM-MA, 102F34, Sm1021, and WSM419. Values represent the mean \pm standard error $(n=$ 10). Letters indicate statistical differences between groups $(P<0.05$, Kruskal-Wallis test). strain Sm2011, strain Rm41, and their derived mutants are largely used in the Medicago research community. However, these $S$. meliloti strains, which were originally isolated from Medicago sativa nodules, are poor symbiotic partners for Jemalong A17 (Terpolilli et al. 2008). These strains efficiently induce nodules but these nodules are not or are only weakly functional and display low nitrogen-fixation activity. Although this is not necessarily a shortcoming in studies that focus on the very early stages of the interaction, their use is problematic in research on the late stages of symbiosis. Therefore, the strain S. medicae WSM419, which was isolated from Medicago murex and seemed to perform better on $M$. truncatula A17, has been proposed as an alternative to Sm1021 (Laguerre et al. 2012; Larrainzar et al. 2014; Liu et al. 2014; Reeve et al. 2010; Terpolilli et al. 2008). On the other hand, no comparative studies of the symbiotic performance of Sinorhizobium strains on M. truncatula subsp. tricycla R108 are available. Therefore, there is a need to identify appropriate bacterial strains interacting efficiently with the two $M$. truncatula accessions Jemalong A17 and R108. In this study, we compared the symbiotic efficiency of four different strains belonging to the two closely related species $S$. meliloti and $S$. medicae on the two $M$. truncatula accessions, using a combination of physiological, histological, and molecular analyses.

\section{RESULTS}

Plant growth phenotypes and nitrogenase activities reflect specific interactions between $M$. truncatula accessions and Sinorhizobium strains.

As a first approach to investigate the effectiveness of the four Sinorhizobium strains, S. meliloti FSM-MA, S. meliloti 102F34, S. meliloti Sm1021, and S. medicae WSM419, plant morphological responses to these strains were assessed in the two M. truncatula accessions Jemalong A17 and R108. The macroscopic phenotypes of five-week-old plants differed between the two Medicago accessions in interaction with the four bacterial strains (Fig. 1A; Supplementary Fig. 1). A17 plants had a higher biomass when inoculated with strains FSM-MA and WSM419 than with the other strains (Fig. 1A and C), whereas R108 plants had a higher biomass when inoculated with FSM-MA and 102F34 than with the other strains (Fig. 1A and D).

In addition, the efficiency of the different plant-rhizobium partnerships could be visualized by the degree of leaf chlorosis, which reflects the level of nitrogen starvation. In the A17 accession, plants inoculated with $102 \mathrm{~F} 34$ or Sm1021 showed pale green, yellowing leaves in contrast to those infected with FSM-MA or WSM419, which had dark green leaves (Fig. 1B). In the R108 accession, leaf yellowing was observed for plants inoculated with Sm1021 and WSM419, whereas the leaves of plants inoculated with strains FSM-MA and 102F34 were dark green (Fig. 1B).

Next, we monitored nitrogen-fixation activity using the acetylene reduction assay (ARA) at 5 weeks postinoculation (wpi) on M. truncatula Jemalong A17 or R108 plants infected with each of the four rhizobial strains. For A17, nitrogenase activity was significantly greater for plants inoculated with FSM-MA and WSM419 than with 102F34 and Sm1021 (Fig. 2A). For R108, the highest nitrogenase activities were observed in plants inoculated with FSM-MA and 102F34 (Fig. 2A). Similar patterns were obtained for total nitrogenase activity per plant and the specific nitrogenase activity per nodule mass, suggesting variations between the strains and hosts in the functioning of the nodules (Fig. 2B).

Together, these results highlight a different ability of the tested Sinorhizobium strains to support plant development and, inversely, the two host accessions respond differently to the panel of tested strains. To extend our observations on M. truncatula, we 
also analyzed the performance of these four Sinorhizobium strains on three different Medicago sativa cultivars and found that the FSM-MA, Sm1021, and 102F34 strains were very efficient on the three cultivars but the WSM419 strain was a weak symbiont for one of the cultivars (Supplementary Fig. 2; data not shown). Thus, taken together, the FSM-MA strain seems to have, among the four tested strains, the broadest host range for optimal symbiotic performance on Medicago species.

\section{The symbiotic efficiency of the interactions between} M. truncatula accessions and Sinorhizobium strains are correlated with nodule developmental parameters.

To explore the differences in the efficiency of symbiotic couples, we analyzed, in detail, the phenotypes of their nodules. Overall, the four strains formed equal numbers of nodules on the two plant accessions, except for strain 102F34 on M. truncatula A17 inducing almost twice as many nodules as the three other strains (Supplementary Fig. 3). In addition, small variations were observed in the total nodule biomass. A higher nodule biomass was observed in A17 plants inoculated with FSM-MA and WSM419 and, in R108, plants inoculated with FSM-MA and 102F34. Together, the quantification of nodule numbers and mass suggests that the differences between the strains are not explained by differences in the induction of nodules but are, rather, related to differences in nodule development.

An easy-to-score marker of nodule functioning is their color Indeed, well-functioning nodules are pink because of the high production of leghemoglobin protein. This oxygen scavenger prevents inactivation of the oxygen-sensitive nitrogenase by maintaining a low free-oxygen concentration in the cytoplasm of the infected cells. At 3 wpi, the nodules were pink on A17 roots infected with the FSM-MA and WSM419 strains and on R108 roots inoculated with the FSM-MA and 102F34 strains, in agreement with the effective nitrogen-fixation activity in these nodules. On the contrary, the nodules of the other host plantSinorhizobium strain combinations were only faintly pink, correlating with the low nitrogenase activity in these associations.
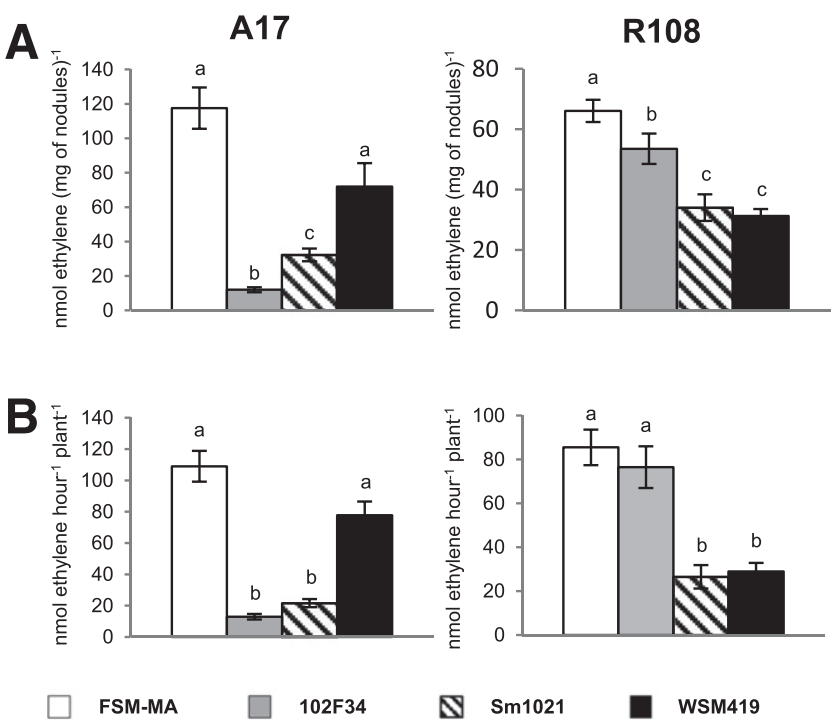

Fig. 2. Nitrogen-fixation efficiency of nodules of Medicago truncatula A17 and R108 inoculated with different Sinorhizobium strains. A, Specific nitrogenase activity (nmol ethylene per hour per milligram of dry nodules) of M. truncatula A17 and R108 at 5 weeks postinoculation (wpi) with bacterial strains FSM-MA, 102F34, Sm1021, and WSM419. B, Total nitrogenase activity (nmol ethylene per hour per plant) of M. truncatula A17 and R108 at 5 wpi with bacterial strains FSM-MA, 102F34, Sm1021, and WSM419. Values represent the mean \pm standard error $(n=10)$. Letters indicate statistical differences between groups $(P<0.05$, Kruskal-Wallis test).
To test whether the defect in symbiotic nitrogen fixation was related to nitrogenase expression, we examined the promoter activity of the nitrogenase reductase nifH gene, using a nifH::GUS ( $\beta$-glucuronidase) reporter fusion. The nifH::GUS expression was induced under symbiotic conditions in all the tested M. truncatula-Sinorhizobium combinations (Supplementary Fig. 4). Although chromogenic staining for GUS activity is not quantitative, this observation demonstrates that, in all combinations, the nitrogenase gene expression is properly activated.

To investigate the histological organization of the nodules in the eight symbiotic couples, nodule sections were stained with the Live/Dead BacLight probe (Fig. 3), which is a mixture of two fluorescent DNA intercalating agents, SYTO9 and propidium iodide (PI). With this staining procedure, living rhizobia are stained with SYTO9 and are green fluorescent whereas dying cells are stained in red with PI. Also the nuclei of the host cells stain with PI in nodule sections (Haag et al. 2011). Zone III of A17 nodules infected with the FSM-MA and WSM419 strains and those of R108 induced by the FSM-MA and 102F34 strains were nearly entirely filled with nodule cells occupied by bacteroids, indicating the invasion of the whole root nodule with viable bacteroids (Fig. 3). In contrast, only a few cell layers full of viable bacteroids were detected in A17 nodules infected with the strains $102 \mathrm{~F} 34$ and Sm1021 or in those of R108 infected with Sm1021 and WSM419 (Fig. 3). Thus the degree of the occupation of the nodules with viable bacteroidcontaining symbiotic nodule cells correlates with the activity of the nodules.

To further investigate the symbiotic nodule cell formation, we measured the ploidy levels of nuclei from nodules harvested from A17 and R108 plants infected with the four studied rhizobia strains, using flow cytometry (Fig. 4). M. truncatula nodules contain nuclei with ploidy levels from $2 \mathrm{C}$ to $64 \mathrm{C}$

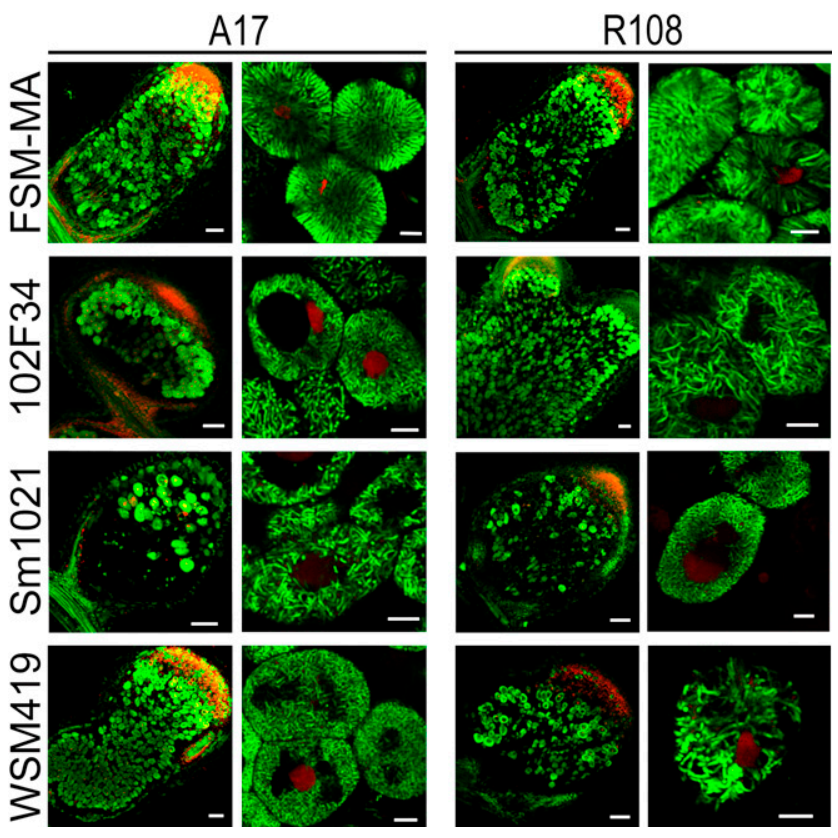

Fig. 3. Histological organization of nodules from Medicago truncatula A17 and R108 inoculated with different Sinorhizobium strains. Nodule sections were stained with the Live/Dead BacLight probe marking viable bacteroids with green fluorescence from SYTO9 and dead bacteria or plant nuclei in red fluorescence by propidium iodide. Representative confocal microscopy pictures of whole nodules at 5 weeks postinoculation or of infected cells in zone III of nodules isolated from A17 and R108 plants inoculated with strains FSM-MA, 102F34, Sm1021, and WSM419. The scale bars represent $100 \mu \mathrm{m}$ (whole nodules) or $10 \mu \mathrm{m}$ (infected cells). 
(Maunoury et al. 2010; Vinardell et al. 2003). The highly endoreduplicated (polyploid) nuclei with 16C, 32C, and 64C genomic DNA content are derived from the symbiotic nodule cells. We calculated an ER index from the flow cytometry measurements to express the relative amounts of $16 \mathrm{C}, 32 \mathrm{C}$, and 64C nuclei in nodules (Maunoury et al. 2010) and compared it among the two $M$. truncatula accessions infected with the four rhizobia strains. We observed a high ER index for the efficient A17 nodules infected with the FSM-MA and WSM419 strains (Fig. 4A) and R108 nodules infected with the FSMMA and 102F34 strains (Fig. 4B), while the other, lessefficient nodules had a low ER index. The number of the highly endoreduplicated cells represented by the ER index were in agreement with the histological analysis. These results indicate a strong correlation between the formation and maintenance of endoreduplicated symbiotic cells and the efficiency of the nodules.

Finally, we also analyzed the differentiation of the bacteroids in the symbiotic cells of the symbiotic couples at 5 wpi. Bacteroids were extracted from the nodules, were stained with PI, and their DNA content was measured by flow cytometry and compared with bacterial cultures of the corresponding strains (Fig. 5A and B). In the A17 nodules, bacteroids with a high DNA content were formed when the inoculation was performed with the FSM-MA and WSM419 strains (Fig. 5A and B). In contrast, in the R108 nodules, bacteroids displayed a higher ploidy level with FSM-MA and 102F34 compared with Sm1021 and WSM419 (Fig. 5A and B). These results demonstrate a correlation between polyploidy level of the bacteroids and the symbiotic efficiency of the interactions.

\section{Incomplete differentiation of the symbiotic cells explains suboptimal symbiotic efficiency of $\mathrm{Sm1021}$ in M. truncatula subsp. tricycla $\mathrm{R} 108$ nodules.}

To gain a more precise understanding of the causes underlying the differences in symbiotic efficiencies between the Sinorhizobium strains, we compared different macroscopic, histological, cytological, physiological, and molecular parameters in nodules. We focused on the associations of Sm1021 and FSM-MA with R108, because these two interactions were among the most contrasting in the previous analysis. Observations were made at 7,14 , and 21 days postinoculation (dpi). Already at $7 \mathrm{dpi}$, better growth could be observed for R108 plants inoculated with FSM-MA than for those inoculated with Sm1021, and this difference became more accentuated at the two later time points (Fig. 6A). This difference could not be explained by different kinetics of nodule induction, because
A

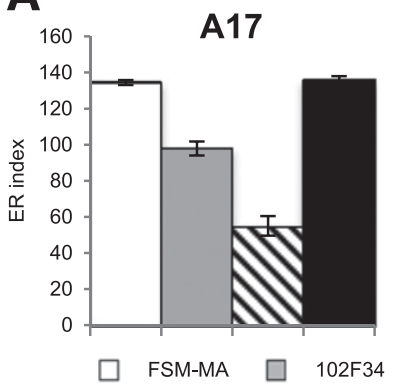

B

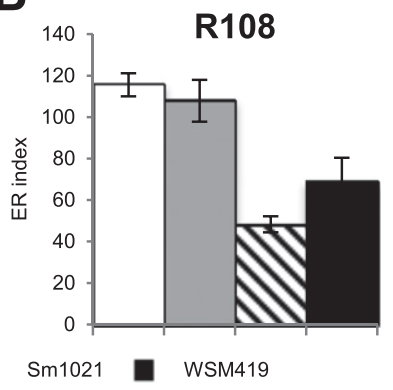

Fig. 4. Nodule ploidy analysis of Medicago truncatula A17 and R108 inoculated with different Sinorhizobium strains. A, Endoreduplication (ER) index of nodule nuclei derived from $M$. truncatula A17. B, ER index of nodule nuclei derived from $M$. truncatula R108. Plants were at 3 weeks postinoculation and were inoculated with the different rhizobia strains FSM-MA, 102F34, Sm1021, and WSM419. The ER index expresses the relative amounts of $16 \mathrm{C}, 32 \mathrm{C}$, and $64 \mathrm{C}$ nuclei in nodules. both plant groups developed the same number of nodules per plant (Fig. 6B). However, the phenotype of the nodules was dramatically different. At all time points, nodules induced by FSM-MA were larger and more intensely colored (Fig. 6C). At 7 dpi, FSM-MA nodules were already pinkish, suggesting that they were active in nitrogen fixation, while Sm1021 nodules were still white or only very faintly pink. These macroscopic observations were corroborated by ARAs, which revealed a higher activity for the FSM-MA-infected nodules than for those infected with Sm1021 at all time points (Fig. 6D). Already at 7 dpi, nitrogenase activity was detectable in FSM-MA nodules while it was close to background levels in Sm1021 nodules. Live/Dead BacLight staining and confocal microscopy revealed that the histological organization of nodules induced by the two strains was very similar (Fig. 6E). Already at $7 \mathrm{dpi}$, nodules infected with both strains displayed typical zonation, with meristem, infection zone, and the zone with symbiotic nodule cells entirely filled with differentiated bacteroids. Nevertheless, determination of the ER index by flow cytometry showed that the level of differentiation of the symbiotic cells in the Sm1021 nodules was lower than in the FSM-MA nodules (Fig. 6F). Thus differences that cannot be observed by microscopy are readily measured by the quantitative flow cytometry analysis of the ER index. Together, these observations demonstrate that both strains induce nodules with equal efficiency, that the organogenesis of nodules infected by both strains is proceeding similarly, but that the differentiation of the symbiotic cells in Sm1021-infected nodules is not advancing to the same extent as in the FSM-MAinfected nodules. To further explore this idea, we analyzed, by reverse transcription-quantitative polymerase chain reaction (RTqPCR), the expression of marker genes (Fig. 6G; Supplementary Fig. 5). Based on temporal expression profiles from microarray transcriptome data (Maunoury et al. 2010) and spatial profiles obtained from laser-capture microdissection coupled to RNA sequencing (Roux et al. 2014), we selected genes that are expressed during early nodule development and in the apical part of the nodule, i.e., in either the meristem, the infection zone, or both (apical markers), genes that are expressed in the infection zone and fixation zone (intermediate markers), and finally, genes that are expressed in the fixation zone only (proximal markers) (Fig. 6G). Interestingly, the apical and intermediate markers were expressed at similar levels in both types of nodule or even more strongly in the Sm1021-infected ones. However, the proximal markers (those expressed in the symbiotic cells) were expressed at much lower levels in the Sm1021-infected nodules than in the FSM-MA-infected nodules, confirming that the Sm1021-infected symbiotic cells are less differentiated than the FSM-MA-infected symbiotic cells. The level of symbiotic cell differentiation is correlated with a strongly reduced expression of the nitrogenaseencoding nifH gene in the Sm1021 bacteroids (Fig. 6G), explaining the suboptimal efficiency of the Sm1021 nodules.

\section{Senescence as a mechanism to control the interactions between $M$. truncatula accessions and Sinorhizobium strains.}

To investigate whether the differential efficiency of the M. truncatula host-Sinorhizobium strain combinations is also correlated with nodule senescence, we characterized the senescence status of 7-wpi nodules of the A17 and R108 plants infected with the four Sinorhizobium strains (Supplementary Fig. 6). A17 nodules induced by FSM-MA or WSM419 were big and pink, indicating that those nodules were healthy, whereas those infected with 102F34 or Sm1021 were small and light green, indicative for an advanced stage of senescence. The green color originates from the accumulation of biliverdin, a degradation product of the heme cofactor of leghemoglobin. R108 formed elongated nodules with all the 
Sinorhizobium strains. However, pink nodules were observed on R108 plants inoculated with FSM-MA or 102F34, whereas the nodules infected with WSM419 or Sm1021 were green at their base.

To further assess a potential link with senescence at a molecular level, we analyzed the expression of the senescence markers $M t C P 2$ and $M t C P 3$ (Van de Velde et al. 2006) in the 7-wpi nodules of M. truncatula A17 and R108 accessions infected with the different Sinorhizobium strains (Fig. 7A and B). Low expression of $\mathrm{MtCP} 2$ and $\mathrm{MtCP} 3$ was observed in nodules infected with FSM-MA on both plants, in A17 nodules infected with WSM419, and R108 nodules infected with 102F34,
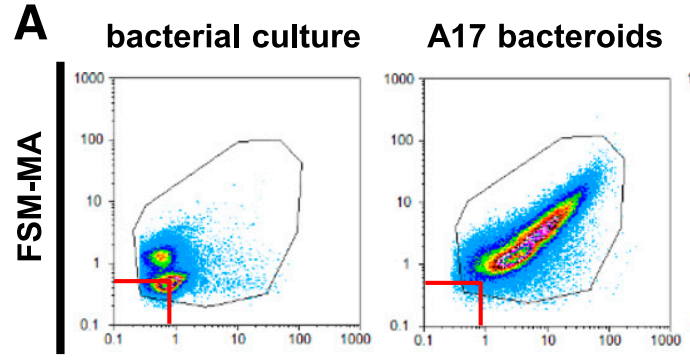

\section{R108 bacteroids}
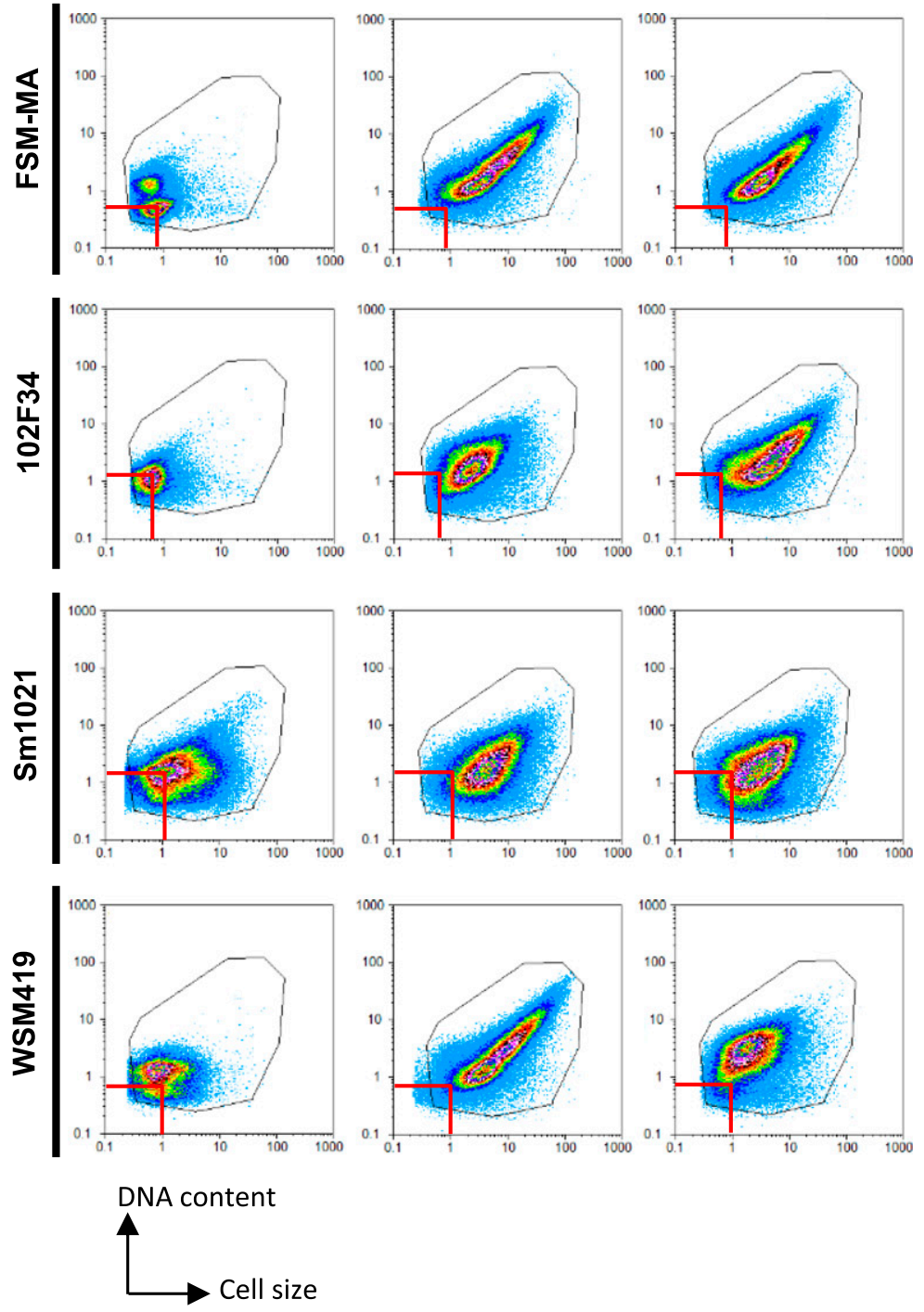

B

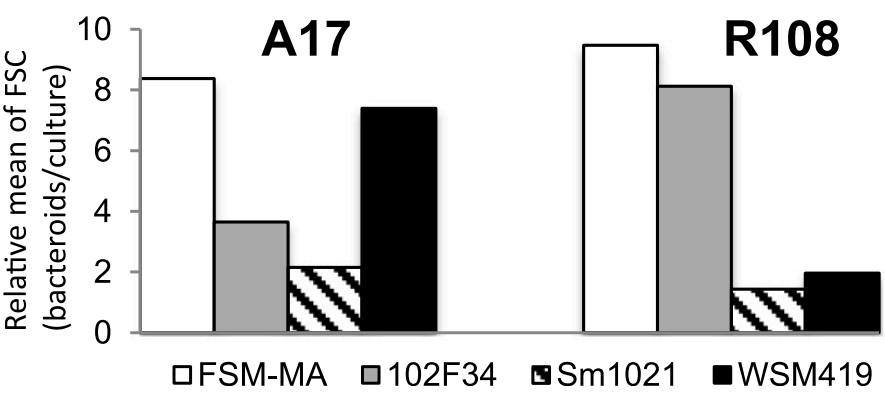

Fig. 5. Bacteroid differentiation analysis of Medicago truncatula A17 and R108 inoculated with different Sinorhizobium strains. A, Flow cytometry analysis of propidium iodide (PI)-stained bacterial cultures of strains FSM-MA, 102F34, Sm1021, and WSM419 or their respective bacteroids isolated from nodules formed on M. truncatula A17 and R108. The $x$ axis represents the forward scatter (cell size) and the $y$ axis corresponds to PI fluorescence (DNA content). The red lines indicate the mean position of the cultured bacteria and highlight the cell enlargement and DNA increase in the bacteroids. $\mathbf{B}$, Increase in cell size of bacteroids, compared with cultured bacteria. The ratio of the mean forward scatter (FSC) of bacteroids to the mean FSC of the cultured bacteria is represented. 

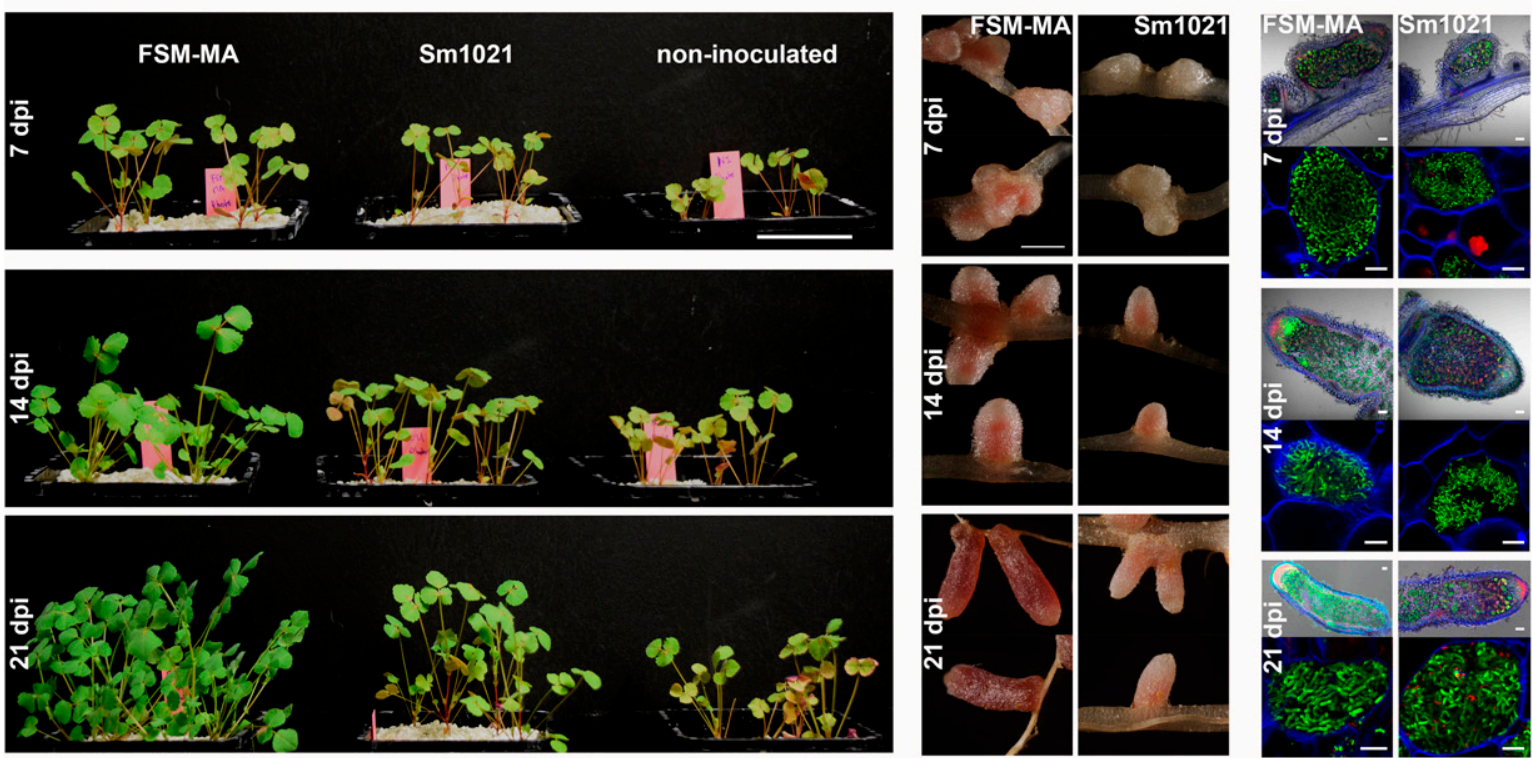

B

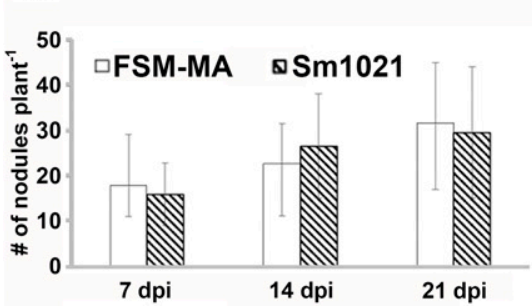

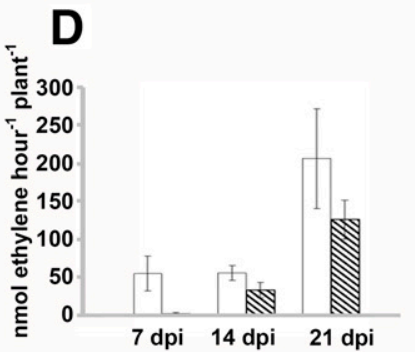
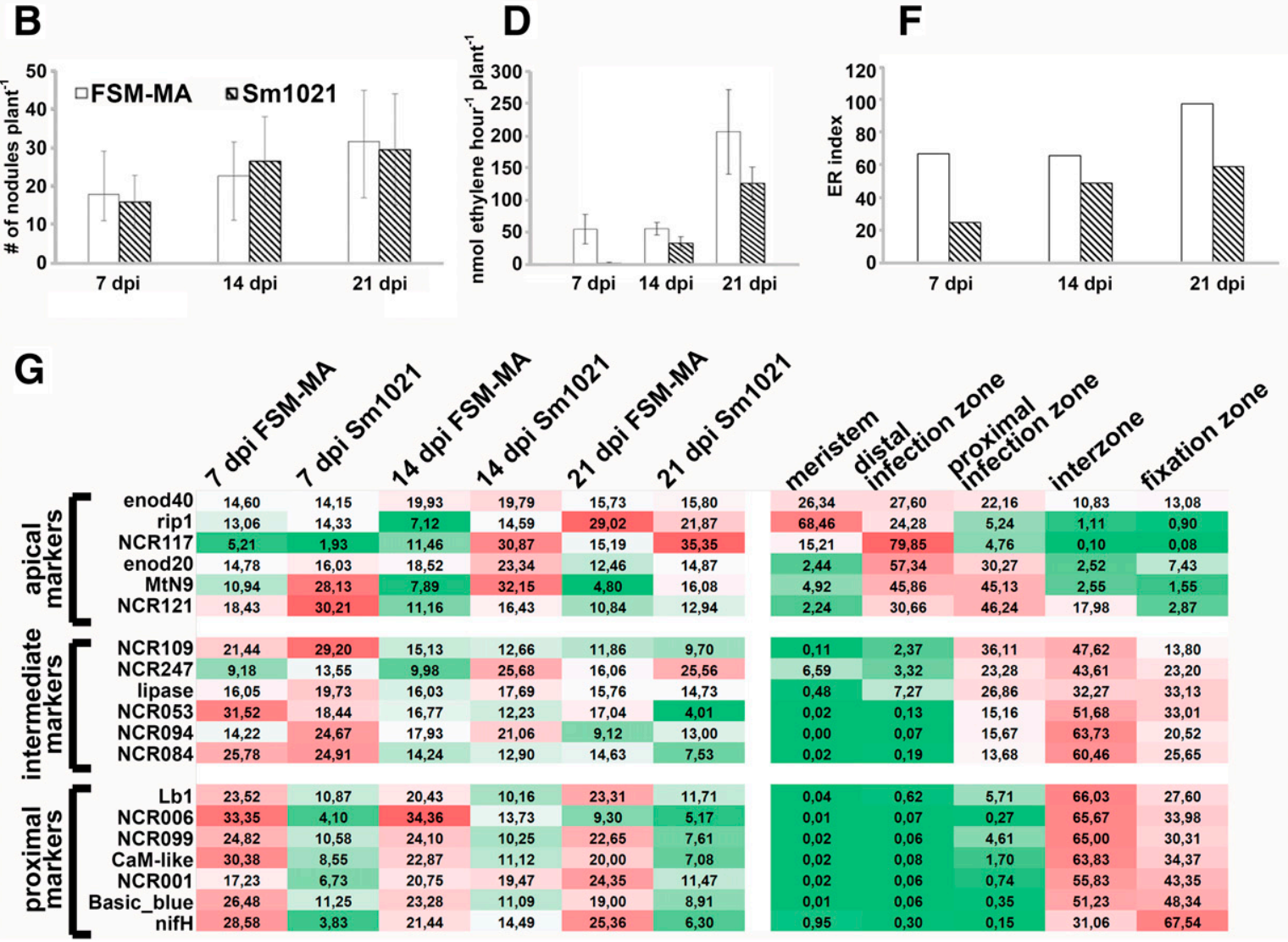

Fig. 6. Kinetics of nodule development in FSM-MA and Sm1021 infected Medicago truncatula subsp. tricycla R108. A, Phenotypes of M. truncatula R108 at 7, 14 , and 21 days postinoculation (dpi) with FSM-MA or Sm1021. All the plants were photographed at the same scale. The scale bar represents $5 \mathrm{~cm}$. B, Number of nodules formed per plant on $M$. truncatula R108 infected by FSM-MA or Sm1021 at 7, 14, and 21 dpi. Values represent the mean \pm standard deviation ( $n=50)$. C, Nodule phenotypes from M. truncatula R108 inoculated with FSM-MA or Sm1021. D, Total nitrogenase activity (nmol ethylene per hour per plant) of M. truncatula R108 infected by FSM-MA or Sm1021 and at 7, 14, and 21 dpi. Values represent the mean \pm standard error $(n=10)$. E, Histological organization of nodules from $M$. truncatula R108 inoculated with FSM-MA or Sm1021. Nodule sections were stained with the Live/Dead BacLight probe marking viable bacteroids with green fluorescence from SYTO9 and dead bacteria or plant nuclei in red fluorescence by propidium iodide. Representative confocal microscopy pictures of whole nodules or of details of infected cells in the zone III of nodules are shown. The scale bars represent $100 \mu \mathrm{m}$ (whole nodules) or $10 \mu \mathrm{m}$ (infected cells). F, Nodule ploidy analysis of M. truncatula R108 inoculated with FSM-MA or Sm1021 at 7, 14, and 21 dpi. The Endoreduplication (ER) index expresses the relative amounts of 16C, 32C, and 64C nuclei in nodules. G, Gene expression heat map of nodule marker genes. Green is weak, red is high relative expression and pale colors are intermediate levels. Expression levels are indicated in the cells and expressed as percentage of the total overall samples. Genes are ordered according to their spatial expression profile in nodules with the top maximum expression in the nodule apex (meristem) and at the bottom maximum expression in the nitrogen-fixation zone of the nodule (root proximal). The genes are grouped in three clusters: apical markers, intermediate markers, and proximal markers. Left heat map, expression determined by reverse transcription-quantitative polymerase chain reaction in $M$. truncatula R108 nodules, at 7, 14, and 21 dpi, infected with FSM-MA or Sm1021. Right heat map, expression determined by RNA-Seq, data extracted from Roux et al. (2014). 
whereas a high accumulation of $M t C P 2$ and $M t C P 3$ transcripts was observed in nodules of both accessions infected with Sm1021, in nodules of A17 infected with 102F34, and in nodules of R108 infected with WSM419. This is in agreement with the visual observation of senescence in nodules and reveals an inverse correlation between activation of nodule senescence and symbiotic efficiency.

\section{DISCUSSION}

In this study, we have compared morphological, histological, cytological, physiological, and molecular parameters in eight different symbiotic associations, formed by two $M$. truncatula accessions and four Sinorhizobium strains. In summary, we find i) a strong plant genotype-bacterial strain variability in symbiotic efficiency, a feature that has been well-documented previously (Laguerre et al. 2012; Larrainzar et al. 2014; Terpolilli et al. $2008)$; ii) a strong correlation between the symbiotic efficiency of the association and the degree of differentiation of both the symbiotic nodule cells and the bacteroids; iii) that, at least in the case of the interaction of Sm1021 with M. truncatula R108, the suboptimal interaction is not the result of poor nodule initiation or nodule organogenesis but of a lower level of differentiation of the symbiotic cells; and iv) that the most widely used strain, Sm1021, performs poorly on both tested M. truncatula accessions but that a newly identified strain, FSM-MA, is an excellent symbiont for the two $M$. truncatula accessions as well as for the tested $M$. sativa cultivars.

\section{Differentiation of symbiotic nodule cells and bacteroids is a major determinant of symbiotic efficiency.}

It is important to note that all eight $M$. truncatulaSinorhizobium couples investigated here produced functional, nitrogen-fixing nodules that were infected with rhizobia. The histological analysis by microscopy and flow cytometry indicated that, in all cases, nodules had the typical organization in the distinct zones and that infected symbiotic cells were formed containing differentiated bacteroids. These observations showed that nodule organogenesis is, in all cases, proceeding normally. At least in the case of infection of R108 with strains Sm1021 and FSM-MA, the kinetics of nodule formation is very similar. The most striking difference between strongly and weakly fixing nodules was the level of symbiotic cell differentiation measured by flow cytometry and expressed by the ER index of the nodules. In the case of infection of R108 with strains Sm1021 and FSMMA, the different level of differentiation was obvious from the earliest measured time point. The lower differentiation of Sm1021-infected symbiotic cells was also obvious from gene expression analysis of marker genes that are specifically expressed in those cells. Moreover, we demonstrated that the degree of bacteroid differentiation, characterized by the level of cell enlargement and DNA amplification, is also positively correlated with the nitrogen-fixation capacity of the tested combinations. These observations suggest thus that the degree of differentiation of both the symbiotic nodule cells and the bacteroids are variable factors that have a strong impact on the efficiency of the symbiosis.

The differentiation of the bacteroids in M. truncatula is determined by the NCR peptides. The symbiotic cells in $M$. truncatula produce a remarkable diversity of several hundred different NCR peptides, each encoded by a distinct gene (Mergaert et al. 2003). Some of these peptides manipulate the cell cycle of the infecting bacteria and induce them into elongated, polyploid bacteroids (Penterman et al. 2014; Van de Velde et al. 2010). However, the large diversity and the fact that many of the NCR peptides continue to be produced after the bacteroid differentiation has been completed, suggest that these

peptides may have additional functions in the bacteroids (Kereszt et al. 2011). Interestingly, it was recently shown that there is a high variation in the expression level and nucleotide sequence of NCR genes among M. truncatula accessions, including R108 and A17 (Nallu et al. 2014). However, the authors compared the inoculation with two different Sinorhizobium strains and observed only subtle differences in NCR expression, suggesting that the plant does not tailor NCR expression according to its symbiotic partner. In contrast, we find, here, that the expression of 10 tested NCR peptides substantially differs between Sm1021-infected and FSM-MA-infected nodules. Thus, it is tempting to speculate that the variations in differentiation of the four Sinorhizobium strains are, in part, related to the differences in NCR production by the A17 and R108 accessions, to bacterial strain-specific profiles of NCR peptides produced by the symbiotic cells, as well as to different responses of these strains to NCR peptides. Nevertheless, we cannot exclude that the differences in NCR expression are the consequence of the distinct differentiation processes rather than their cause.

The fact that many legume species lack $N C R$ genes and, therefore, do not impose a bacteroid differentiation process by cell elongation and genome amplification demonstrates that this bacterial differentiation process is not required per se for the symbiosis to be functional. On the other hand, the enormous investment of the host plant in NCR production has been taken for an indication that the NCR-mediated bacteroid differentiation process improves the efficiency of the symbiosis (Kereszt et al. 2011; Kondorosi et al. 2013). Our observation that the efficiency of the symbiosis correlates with the degree of bacteroid differentiation is in agreement with this hypothesis. It will be of great interest to determine if the connection between the nitrogen-fixation capacity and bacteroid differentiation by elongation and DNA amplification can be generalized to other legume-rhizobium interactions that have a similar bacteroid differentiation mechanism, i.e., in legumes of the inverted repeat-lacking and Dalbergoid clades (Czernic et al. 2015; Guefrachi et al. 2015; Kondorosi et al. 2013).

A notable difference between strongly and weakly fixing nodules from our analyses was the maintenance of the symbiotic cells. In the efficient symbiotic couples, older nodules were entirely filled with bacteroid-containing symbiotic cells, contrary to the less efficient ones, in which only a few cell layers of symbiotic cells were present while the older parts of the nodule seemed to be weakly infected. Strikingly, senescence of nodule tissues is exacerbated in the less-efficient host plant-bacteria

A

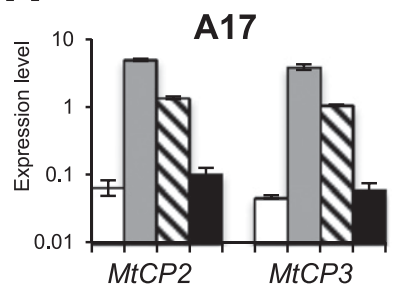

$\square$ FSM-MA $\square$ 102F34 QSm1021 —WSM419

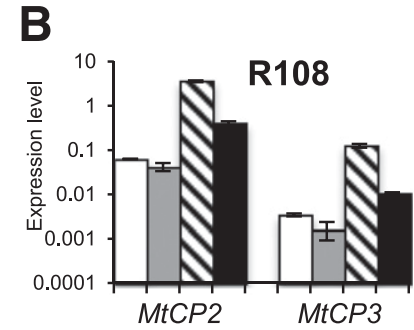

Fig. 7. Expression of the senescence-related nodulation markers $M t C P 2$ and $M t C P 3$ in nodules from Medicago truncatula R108 and A17 inoculated with the different Sinorhizobium strains at a late developmental stage. A, $M t C P 2$ and $M t C P 3$ expression in A17 nodules 7 weeks postinoculation (wpi) with the bacterial strains FSM-MA, 102F34, Sm1021, and WSM419, using reverse transcription-quantitative polymerase chain reaction. B, $M t C P 2$ and $M t C P 3$ expressions in 7-wpi R108 nodules. Bars represent standard error from three biological replicates of pools of nodules from four to eight plants and two technical replicates. 
combinations. This senescence possibly corresponds to a process of "sanctions" imposed by the host on the symbionts, with incomplete bacteroid and symbiotic nodule cell differentiation. Such ineffective or less-effective nitrogen fixers can be viewed, from the plant perspective, as cheaters that attempt to unduly gain benefit from the host (Kiers et al. 2003; Oono et al. 2011). The senescence could be induced by the suboptimal nitrogen supply provided by the bacteria to its plant partner, similarly to the physiological process of senescence activation in leaves by low nitrogen supply (Balazadeh et al. 2014). Determining the level of nodule bacteria capable of surviving from senescent nodules would be necessary to demonstrate that the senescence observed in the inefficient symbiotic couples indeed corresponds to host sanctions.

\section{Strain differences affecting symbiotic efficiency.}

A previous study described strain-genotype specificity in the $S$. meliloti-M. truncatula interaction with a different set of strains and plant accessions and has attributed this specificity to structural differences of the succinoglycan oligosaccharides produced by the studied strains (Simsek et al. 2007). Succinoglycan is an exopolysaccharide produced by $S$. meliloti. Moreover, overproduction of succinoglycan has been shown to slightly improve the symbiotic productivity of S. meliloti Sm1021 on M. truncatula A17 (Jones 2012). We noticed that, when grown on agar plates, the four strains included in this study greatly differed in the production of exopolysaccharide-containing slime. Notably, strains FSMMA and WSM419 were very strong producers while Sm1021 and 102F34 were not. Therefore, we cannot exclude a contribution of differences in succinoglycan production by Sinorhizobium strains in the here-described specific interactions. Nevertheless, exopolysaccharide production cannot be the only factor determining the different performance of the strains, because the weak exopolysaccharide-producing strain 102F34 performs better on M. truncatula R108 than the strong producer WSM419.

The different behavior of the four strains could be related to a different sensibility of the strains to the bacteroid-inducing NCR peptides. The bacterial targets for the NCR peptides and the molecular mechanism that lead to the differentiated bacteroid state remain largely unknown. Nevertheless, a few key actors have been identified. These are BacA, a peptide transporter providing protection against the antimicrobial activity of the NCR peptides (Haag et al. 2011), CtrA, a master cell cycle regulator whose inactivation by NCR peptides (by direct or indirect interactions) results in the inhibition of cell division and the amplification of the DNA content (Penterman et al. 2014; Pini et al. 2015), and peptidases, such as HrrP produced by certain rhizobial strains, which degrade NCR peptides, allowing rhizobia to escape or reduce differentiation (Price et al. 2015). Other cellular targets of NCR peptides have been identified, but their precise role in the bacteroid differentiation process is still not entirely clear (Farkas et al. 2014). It is not unlikely that molecular differences in one or more of these NCR targets, reducing or enhancing their interaction with the host NCR peptides, are at the origin of the different levels of differentiation of the four strains analyzed here.

We recently obtained the genome sequence of the novel strain FSM-MA (unpublished). Its sequence is very close to the sequence of Sm1021, with an average sequence identity of $99.4 \%$, but, interestingly, the most important difference between the two strains is located in the pSymA chromid, which is about 80,000 bp larger in strain FSM-MA. The chromid pSymA is the location of the major symbiotic functions of Sinorhizobium meliloti strains. Comparative genomics between
Sm1021 and FSM-MA and, particularly, between their pSymA chromids has the potential to identify, in FSM-MA, novel bacterial symbiotic genes and genes that are associated with the exceptional symbiotic performance of this strain.

\section{S. meliloti FSM-MA as a strain of choice for the study of nodulation in M. truncatula.}

In conclusion, we propose the recently sequenced FSM-MA strain as a good choice for future symbiosis research with both M. truncatula A17 and R108. Past genetic screens have successfully identified symbiotic mutants in both $M$. truncatula A17 and R108 infected with strain Sm1021 or its sister strain Sm2011 (Pislariu et al. 2012; Starker et al. 2006). However, it is possible that mutants have been overlooked, by the use of these strains, that could have been identified using a more efficient strain such as FSM-MA. In addition, strain FSM-MA could be of great utility in reverse genetics approaches that use RNA interference-based gene knockdown to study the symbiotic role of candidate genes. The use of a highly efficient strain such as FSM-MA might be particularly critical for studies that focus on late stages of nodule development, including host cell differentiation, bacteroid differentiation, or nodule senescence, because the less-efficient strains, as we show here, induce nodules with suboptimal differentiation and early senescence, even in the wild-type host. Bacterial symbiotic mutants, which are extensively used to dissect the symbiotic process, are not yet available in the FSM-MA strain. However, this shortcoming should not be a serious obstacle in light of the available genome sequence of the strain, the ease of the creation of mutants in Sinorhizobium strains, and the broad knowledge of S. meliloti symbiotic functions that could be translated to this novel interesting strain. Finally, future genetic screens in the bacterial partner, such as screens with the novel powerful method known as transposon insertion sequencing or Tn-seq (Chao et al. 2016), aiming to identify bacterial genetic determinants for nodule occupancy, bacteroid differentiation, chronic infection, and nitrogen fixation, could be better done with a strain such as FSM-MA rather than Sm1021.

\section{MATERIALS AND METHODS}

\section{Bacterial strains and growth conditions.}

Four Sinorhizobium strains were used in this study: S. meliloti Sm1021 (Galibert et al. 2001); S. meliloti 102F34, a commercial strain from Nitragin (Milwaukee, WI) with unknown origin that has been used in older studies on Medicago nodulation (Ditta et al. 1980; Pocard et al. 1997); S. meliloti FSM-MA (Faculté Sciences Meknes), which was isolated from Medicago arborea nodules by one of us (J. Ibijbijen, personal communication) and was recently sequenced (unpublished), and S. medicae WSM419, which was isolated from Medicago murex nodules (Reeve et al. 2010).

Bacterial strains were grown in YEB medium $(0.5 \%$ beef extract, $0.1 \%$ yeast extract, $0.5 \%$ peptone, $0.5 \%$ sucrose, $0.04 \%$ $\left.\mathrm{MgSO}_{4} \cdot 7 \mathrm{H}_{2} \mathrm{O}, \mathrm{pH} 7.5\right)$ at $30^{\circ} \mathrm{C}$. Growth media were supplemented with the appropriate antibiotics, streptomycin at $100 \mu \mathrm{g} \cdot \mathrm{ml}^{-1}$ for $S$. meliloti Sm1021 and chloramphenicol at $25 \mu \mathrm{g} \cdot \mathrm{ml}^{-1}$ for $S$. medicae WSM419. S. meliloti FSM-MA and $S$. meliloti $102 \mathrm{~F} 34$ were grown without antibiotics. For plant inoculation, cultures were centrifuged and bacterial pellets were resuspended in water at an optical density at $600 \mathrm{~nm}$ $\left(\mathrm{OD}_{600}\right)=0.05$.

\section{Plant material and growth conditions.}

Two accessions of Medicago truncatula, the Jemalong A17 reference (Young et al. 2011) and R108 (Hoffmann et al. 1997), were used in this study. The Medicago sativa accessions were 
the commercial cultivars Nagyszenas (Hungary), Sitel (France), and Gabès (Tunisia).

For nodulation experiments, Medicago seeds were scarified with sulphuric acid for $3 \mathrm{~min}$, were surface-sterilized with bayrochlore (Bayrol, chlorifix, 0.825\% wt/vol) for $20 \mathrm{~min}$, were soaked in sterile water, and were then stratified for 5 days at $4{ }^{\circ} \mathrm{C}$ in the dark on solid medium (Bacto agar, $1.5 \%$ ), to ensure uniform germination. Seedlings were transferred to perlite/sand ( $3: 1 \mathrm{vol} / \mathrm{vol})$ for a week $\left(24^{\circ} \mathrm{C}\right.$, photoperiod $16 \mathrm{~h}$ of light and $8 \mathrm{~h}$ of dark, humidity 60\%) and were inoculated with $50 \mathrm{ml}$ of the appropriate bacterial culture $\left(\mathrm{OD}_{600}=0.05\right)$ per pot, each pot containing five plantlets. Plants were watered with a commercial N-free fertilizer (PlantProd solution [N-P-K, 015-40; Fertil] at $1 \mathrm{~g}$ per liter).

For macroscopic and microscopic analysis, seedlings were transferred to square petri dishes $(12 \times 12 \mathrm{~cm})$ containing solid Fahreus medium (Truchet et al. 1985). After 5 days, plantlets were inoculated with the appropriate rhizobium strain using $10 \mathrm{ml}$ of bacterial suspension $\left(\mathrm{OD}_{600}=0.05\right)$ per plate.

\section{Nitrogenase activity assay.}

Nitrogen-fixation activity was evaluated using the ARA as described by Koch and Evans (1966). Whole nodulated root systems were collected at the indicated times after rhizobium inoculation and were incubated with $250 \mu \mathrm{l}$ of acetylene for $1 \mathrm{~h}$ at room temperature in a $10-\mathrm{ml}$ air-tight glass vial with rubber stop. After incubation, $250 \mu \mathrm{l}$ of gas mixture was removed from the vial and was injected in a gas chromatography system (7820A; Agilent Technology) to evaluate ethylene production, assessed as the area under the ethylene peak in the chromatogram. Two biological replicates were carried out with 10 plants per condition. The nitrogenase activity was calculated as ARA units (nanomoles ethylene per hour per plant and nanomoles ethylene per milligram of fresh nodule weight). Negative controls were tested by incubating $250 \mu \mathrm{l}$ of acetylene without plant and noninoculated plants, which never produced detectable levels of ethylene.

\section{nifH promoter activity.}

Three-day-old $M$. truncatula seedlings were inoculated with the four different rhizobia strains, each carrying the nifH::GUS reporter construct. Nodules were collected at 3 wpi and were fixed with $4 \%$ formaldehyde in $1 \times$ phosphate buffered saline (PBS) ( $\mathrm{pH} 7.4$ ) for $30 \mathrm{~min}$ on ice, were rinsed three times for $10 \mathrm{~min}$ in $1 \times \mathrm{PBS}$ ( $\mathrm{pH} 7.4$ ), and were embedded in agarose $5 \%$ (wt/vol) (SeaKem LE agarose; Lonza). Tissue sections of $50 \mu \mathrm{m}$ were prepared with a Zeiss MICROM HM650V vibratome. GUS staining was carried out as described by Vanstraelen et al. (2009) and was allowed to proceed for $15 \mathrm{~min}$ at $37^{\circ} \mathrm{C}$. Nodule sections were examined under a Zeiss Axiovert $40 \mathrm{CFL}$ microscope with $10 \times$ objective.

\section{Macroscopic analysis.}

Plants were photographed and collected 5 wpi for macroscopic analysis. Nodulated roots and aerial parts were weighed (fresh weight).

\section{In vivo Live/Dead staining and confocal microscopy.}

Three-week-old nodules from in vitro cultivated plants were harvested, were embedded in agarose $6 \%$ (wt/vol), and were prepared for Live/Dead staining as described by Haag et al. (2011). Nodule sections $(70 \mu \mathrm{m})$ were prepared with a Leica VT1200S vibratome (Leica Microsystems $\mathrm{GmbH}$ ) and were incubated for $20 \mathrm{~min}$ in Live/Dead staining solution $(5 \mu \mathrm{M}$ SYTO9 and $30 \mu \mathrm{M}$ PI in $50 \mathrm{mM}$ Tris- $\mathrm{HCl}$ buffer, $\mathrm{pH} 7.0$ [Live/Dead BacLight, Invitrogen]) containing 0.01\% Calcofluor White M2R (Sigma). Sections were removed from the staining solution, were rinsed of excess dye in water, and were mounted in $50 \mathrm{mM}$ Tris- $\mathrm{HCl}$ buffer, $\mathrm{pH} 7.0$, for microscopic observations. Images were taken using a Leica confocal laser scanning microscope TCS SP2.

\section{Bacteroid isolation.}

Bacteroids were purified as previously described (Mergaert et al. 2006). Nodules were harvested in ice-cold bacteroid extraction buffer (BEB) $(125 \mathrm{mM} \mathrm{KCl}, 50 \mathrm{mM} \mathrm{Na}$-succinate, $50 \mathrm{mM}$ $\mathrm{N}$-tris(hydroxymethyl)methyl-2-aminoethanesulfonic acid, $\mathrm{pH} 7.0$ ) containing $0.1 \%$ bovine serum albumin and was ground with a precooled mortar and pestle. The slurry was centrifuged at $100 \times g$ for $10 \mathrm{~min}$ to remove plant debris. The upper phase was centrifuged at 3,600 $\times g$ for $10 \mathrm{~min}$, the supernatant was removed, and the bacteroid pellet was resuspended in BEB. The bacteroids were further purified by Percoll density gradient centrifugation. The bacteroid suspension (100 to $500 \mu \mathrm{l}$ ) was layered on the top of $7 \mathrm{ml}$ of $70 \%$ Percoll in an ultracentrifuge tube and was centrifuged for $30 \mathrm{~min}$ at $48,000 \times g$ at room temperature. The bacterial band was carefully removed from the upper part of the gradient, using a Pasteur pipette, was diluted in excess BEB, and was centrifuged again at 3,600 $\times g$ for $10 \mathrm{~min}$. Supernatant was removed and the bacteroid pellet was resuspended in BEB.

\section{Flow cytometry measurements.}

Nodule ploidy levels were assessed as described (Maunoury et al. 2010). Nodules were chopped with a razor blade in buffer (45 mM $\mathrm{MgCl}_{2}, 30 \mathrm{mM}$ trisodium citrate, $20 \mathrm{mM} \mathrm{3-}(\mathrm{N}$ morpholino)propanesulfonic acid, $0.1 \%$ Triton $\mathrm{X}-100$, $\mathrm{pH} 7.2$ to 7.4) to break cells and release nuclei. Suspensions were then filtered through 30- $\mu \mathrm{m}$ Celltrics filters (Partec). Nuclei were stained by $4^{\prime}, 6$-diamidino-2-phenylindole (DAPI) $\left(5 \mu \mathrm{g} \mathrm{ml}^{-1}\right)$ and was analyzed using a Beckman MoFlow Astrios (Beckman Coulter) flow cytometer with a 488-nm laser for scattering and a 355-nm laser for DAPI excitation. Nuclei were gated in a DNA/side scatter plot (DAPI versus SSC) according to their DNA content and granularity. ER index was calculated based on the level of the $16 \mathrm{C}, 32 \mathrm{C}$, and $64 \mathrm{C}$ endoreduplicated nodule nuclei according to the following formula: (\% 16C nuclei) $\times 3+$ $(\%$ 32C nuclei $) \times 4+(\%$ 64C nuclei) $\times 5$ (Maunoury et al. 2010).

Prior to flow cytometry, purified bacteroids were fixed by heat $\left(70^{\circ} \mathrm{C}\right.$ for $\left.15 \mathrm{~min}\right)$ and were stained with PI $\left(50 \mu \mathrm{g} \mathrm{ml}^{-1}\right)$. PI fluorescence was analyzed with excitation at $561 \mathrm{~nm}$, using a Partec CyFlow Space and the Summit 6.2 software. Minimally, 100,000 single events were measured per sample, and a PI fluorescence histogram was used to assess the DNA ploidy level of the bacteroids. Cultured bacteria of the four strains were used as reference samples.

\section{RT-qPCR analysis.}

Total RNA was isolated from $M$. truncatula nodules (1 mg) using the Plant RNeasy mini kit (Qiagen) and was subjected to DNase I treatment (Fermentas). The first-strand cDNA was synthesized from $1 \mu \mathrm{g}$ of total RNA, using the SuperScript II first strand synthesis kit, according to the manufacturer's instructions (Invitrogen). First-strand cDNA of plant RNA was obtained with a poly-dT primer, while cDNA of bacterial RNA was obtained with a random hexamer primer. Real-time RTqPCR reactions were performed on a Roche Light Cycler 480, using the Light Cycler fast start DNA master SYBR green I kit according to manufacturer's instructions (Roche). Cycling conditions were as follows: $95^{\circ} \mathrm{C}$ for $10 \mathrm{~min}, 50$ cycles at $95^{\circ} \mathrm{C}$ for $5 \mathrm{~s}, 58^{\circ} \mathrm{C}$ for $5 \mathrm{~s}$, and $72^{\circ} \mathrm{C}$ for $15 \mathrm{~s}$. Three independent biological experiments and two technical replicates (based on two independent cDNA syntheses derived from the same RNA sample) were performed in all cases. The two used plant reference genes, MtACT (actin 11) and $M t H 3 L$ (histone 3-like) 
(Plet at al. 2011), were previously defined using GeNorm software. Primers used for MtACT expression: ACCCAAAG CATCAAATAATAAGTCAACC (forward) and TGGCATCA CTCAGTACCTTTCAACTG (reverse). Primers used for $M t H 3 L$ expression: ATTCCAAAGGCGGCTGCATA (forward) and CTTTGCTTGGTGCTGTTTAGATGG (reverse). Primers used for $M t C P 2$ expression: CATCTTACCCTACTGCTTAAA TGC (forward) and AACTAGAAACCATGATGAATGTAGC (reverse). Primers used for $M t C P 3$ expression: TGGAAGC ATCTTACCCTACTG (forward) and ATATACATAAATCG CAAATCACATTC (reverse) (Pérez Guerra et al. 2010). The primers for the nodule marker genes were reported previously (Maunoury et al. 2010). The reference for bacterial gene expression was the $16 \mathrm{~S}$ ribosomal RNA amplified with the primers GCAGAACCTTACCAGCCCTT (forward) and TATC ACCGGCAGTCCCCTTA (reverse). The nifH genes of Sm1021 and FSM-MA differ only in two nucleotides, and the primers CGGCGTTATCACCTCGATCA (forward) and CGATGTTG TTGGCGGCATAG (reverse) amplified a $100 \%$ identical region of the gene. Expression levels were calculated using three biological replicates and two technical replicates, normalized with the expression of the reference genes.

\section{Statistical test.}

For each experiment, two independent biological replicates with 10 to 15 plants each were performed. A nonparametric Kruskal-Wallis test (available in XLSTAT software) was used.

\section{ACKNOWLEDGMENTS}

We thank J. Ronfort and J.-M. Prosperi for providing M. truncatula seeds. We are indebted to M. Amar (CNRST Rabat, Morocco) and P. Ratet (IPS2, France) for providing bacterial strain FSM-MA. We thank M. Bourge (Imagerie Gif, I2BC, Gif-sur-Yvette, France) for help with the flow cytometry experiments. Imagerie Gif is supported by the "Infrastructures en Biologie Santé et Agronomie" (IBiSA), the "Agence Nationale de la Recherche" (ANR), under Investments for the Future programs "FranceBioImaging infrastructure" (ANR-10-INSB-04-01), "Saclay Plant Sciences" (ANR-10-LABX-0040-SPS), and also the Conseil Général de l'Essonne. The IPS2 and I2BC institutes benefit from the support of the LabEx Saclay Plant Sciences-SPS (ANR-10-LABX-0040-SPS). T. Kazmierczak, F. Lamouche, and Q. Barrière were supported by Université Paris-Sud, and T. Kazmierczak also by the Agence Nationale de la Recherche. M. Nagymihály was supported by a fellowship from Campus France and I. Guefrachi by the France-Tunisia "Comité Mixte de Coopération Universitaire" (CMCU), project14G0817. Work by the F. Frugier team (V. Gruber and T. Kazmierczak) was supported by the Agence Nationale de la Recherche, the LabEx Saclay Plant Sciences-SPS, and the Lidex Plant Phenotyping and Engineering Pipeline-3P. The P. Mergaert team was funded by grant ANR-13-BSV7-0013.

\section{LITERATURE CITED}

Alunni, B., and Gourion, B. 2016. Terminal bacteroid differentiation in the legume-rhizobium symbiosis: nodule-specific cysteine-rich peptides and beyond. New Phytol. 211:411-417.

Balazadeh, S., Schildhauer, J., Araújo, W. L., Munné-Bosch, S., Fernie, A. R., Proost, S., Humbeck, K., and Mueller-Roeber, B. 2014. Reversal of senescence by $\mathrm{N}$ resupply to $\mathrm{N}$-starved Arabidopsis thaliana: transcriptomic and metabolomic consequences. J. Exp. Bot. 65:3975-3992.

Chao, M. C., Abel, S., Davis, B. M., and Waldor, M. K. 2016. The design and analysis of transposon insertion sequencing experiments. Nat. Rev. Microbiol. 14:119-128.

Cheng, X., Wang, M., Lee, H. K., Tadege, M., Ratet, P., Udvardi, M., Mysore, K. S., and Wen, J. 2014. An efficient reverse genetics platform in the model legume Medicago truncatula. New Phytol. 201:1065-1076.

Czernic, P., Gully, D., Cartieaux, F., Moulin, L., Guefrachi, I., Patrel, D., Pierre, O., Fardoux, J., Chaintreuil, C., Nguyen, P., Gressent, F., Da Silva, C., Poulain, J., Wincker, P., Rofidal, V., Hem, S., Barrière, Q., Arrighi, J. F., Mergaert, P., and Giraud, E. 2015. Convergent evolution of endosymbiont differentiation in Dalbergioid and inverted repeat-lacking clade legumes mediated by nodulespecific cysteine-rich peptides. Plant Physiol. 169:1254-1265.
Ditta, G., Stanfield, S., Corbin, D., and Helinski, D. R. 1980. Broad host range DNA cloning system for gram-negative bacteria: construction of a gene bank of Rhizobium meliloti. Proc. Natl. Acad. Sci. U.S.A. 77: 7347-7351.

Farkas, A., Maróti, G., Durgő, H., Györgypál, Z., Lima, R. M., Medzihradszky, K. F., Kereszt, A., Mergaert, P., and Kondorosi, É. 2014. Medicago truncatula symbiotic peptide NCR247 contributes to bacteroid differentiation through multiple mechanisms. Proc. Natl. Acad. Sci. U.S.A. 111:5183-5188.

Ferguson, B. J., Indrasumunar, A., Hayashi, S., Lin, M.-H., Lin, Y.-H., Reid, D. E., and Gresshoff, P. M. 2010. Molecular analysis of legume nodule development and autoregulation. J. Integr. Plant Biol. 52:61-76.

Galibert, F., Finan, T. M., Long, S. R., Puhler, A., Abola, P., Ampe, F., BarloyHubler, F., Barnett, M. J., Becker, A., Boistard, P., Bothe, G., Boutry, M. Bowser, L., Buhrmester, J., Cadieu, E., Capela, D., Chain, P., Cowie, A., Davis, R. W., Dreano, S., Federspiel, N. A., Fisher, R. F., Gloux, S., Godrie, T., Goffeau, A., Golding, B., Gouzy, J., Gurjal, M., HernandezLucas, I., Hong, A., Huizar, L., Hyman, R. W., Jones, T., Kahn, D., Kahn, M. L., Kalman, S., Keating, D. H., Kiss, E., Komp, C., Lelaure, V., Masuy, D., Palm, C., Peck, M. C., Pohl, T. M., Portetelle, D., Purnelle, B., Ramsperger, U., Surzycki, R., Thebault, P., Vandenbol, M., Vorholter, F. J., Weidner, S., Wells, D. H., Wong, K., Yeh, K. C., and Batut, J. 2001. The composite genome of the legume symbiont Sinorhizobium meliloti. Science 293:668-672.

Guefrachi, I., Pierre, O., Timchenko, T., Alunni, B., Barrière, Q., Czernic, P., Villaécija-Aguilar, J. A., Verly, C., Bourge, M., Fardoux, J., Mars, M., Kondorosi, E., Giraud, E., and Mergaert, P. 2015. Bradyrhizobium BclA is a peptide transporter required for bacterial differentiation in symbiosis with Aeschynomene legumes. Mol. Plant-Microbe Interact 28:11551166

Haag, A. F., Baloban, M., Sani, M., Kerscher, B., Pierre, O., Farkas, A., Longhi, R., Boncompagni, E., Hérouart, D., Dall'angelo, S., Kondorosi, E., Zanda, M., Mergaert, P., and Ferguson, G. P. 2011. Protection of Sinorhizobium against host cysteine-rich antimicrobial peptides is critical for symbiosis. PLoS Biol. 9:e1001169.

Hoffmann, B., Trinh, T. H., Leung, J., Kondorosi, A., and Kondorosi, E. 1997. A new Medicago truncatula line with superior in vitro regeneration, transformation, and symbiotic properties isolated through cell culture selection. Mol. Plant-Microbe Interact 10:307-315.

Jones, K. M. 2012. Increased production of the exopolysaccharide succinoglycan enhances Sinorhizobium meliloti 1021 symbiosis with the host plant Medicago truncatula. J. Bacteriol. 194:4322-4331.

Kereszt, A., Mergaert, P., and Kondorosi, E. 2011. Bacteroid development in legume nodules: evolution of mutual benefit or of sacrificial victims? Mol. Plant-Microbe Interact 24:1300-1309.

Kiers, E. T., Rousseau, R. A., West, S. A., and Denison, R. F. 2003. Host sanctions and the legume-rhizobium mutualism. Nature 425:78-81.

Koch, B., and Evans, H. J. 1966. Reduction of acetylene to ethylene by soybean root nodules. Plant Physiol. 41:1748-1750.

Kondorosi, E., Mergaert, P., and Kereszt, A. 2013. A paradigm for endosymbiotic life: cell differentiation of Rhizobium bacteria provoked by host plant factors. Annu. Rev. Microbiol. 67:611-628.

Laguerre, G., Heulin-Gotty, K., Brunel, B., Klonowska, A., Le Quéré, A., Tillard, P., Prin, Y., Cleyet-Marel, J.-C., and Lepetit, M. 2012. Local and systemic N signaling are involved in Medicago truncatula preference for the most efficient Sinorhizobium symbiotic partners. New Phytol. 195: 437-449.

Larrainzar, E., Gil-Quintana, E., Seminario, A., Arrese-Igor, C., and González, E. M. 2014. Nodule carbohydrate catabolism is enhanced in the Medicago truncatula A17-Sinorhizobium medicae WSM419 symbiosis. Front. Microbiol. 5:447.

Liu, J., Yang, S., Zheng, Q., and Zhu, H. 2014. Identification of a dominant gene in Medicago truncatula that restricts nodulation by Sinorhizobium meliloti strain Rm41. BMC Plant Biol. 14:167.

Łotocka, B., Kopcińska, J., and Skalniak, M. 2012. Review article: The meristem in indeterminate root nodules of Faboideae. Symbiosis 58: 63-72.

Maunoury, N., Redondo-Nieto, M., Bourcy, M., Van de Velde, W., Alunni, B., Laporte, P., Durand, P., Agier, N., Marisa, L., Vaubert, D., Delacroix, H., Duc, G., Ratet, P., Aggerbeck, L., Kondorosi, E., and Mergaert, P. 2010. Differentiation of symbiotic cells and endosymbionts in Medicago truncatula nodulation are coupled to two transcriptome-switches. PLoS One 5:e9519.

Mergaert, P., Nikovics, K., Kelemen, Z., Maunoury, N., Vaubert, D., Kondorosi, A., and Kondorosi, E. 2003. A novel family in Medicago truncatula consisting of more than 300 nodule-specific genes coding for small, secreted polypeptides with conserved cysteine motifs. Plant Physiol. 132:161-173. 
Mergaert, P., Uchiumi, T., Alunni, B., Evanno, G., Cheron, A., Catrice, O., Mausset, A. E., Barloy-Hubler, F., Galibert, F., Kondorosi, A., and Kondorosi, E. 2006. Eukaryotic control on bacterial cell cycle and differentiation in the Rhizobium-legume symbiosis. Proc. Natl. Acad. Sci. U.S.A. 103:5230-5235.

Nallu, S., Silverstein, K. A., Zhou, P., Young, N. D., and Vandenbosch, K. A. 2014. Patterns of divergence of a large family of nodule cysteinerich peptides in accessions of Medicago truncatula. Plant J. 78:697-705.

Oldroyd, G. E., and Dixon, R. 2014. Biotechnological solutions to the nitrogen problem. Curr. Opin. Biotechnol. 26:19-24.

Oldroyd, G. E., and Downie, J. A. 2008. Coordinating nodule morphogenesis with rhizobial infection in legumes. Annu. Rev. Plant Biol. 59:519-546.

Oono, R., Anderson, C. G., and Denison, R. F. 2011. Failure to fix nitrogen by non-reproductive symbiotic rhizobia triggers host sanctions that reduce fitness of their reproductive clonemates. Proc. Biol. Sci. 278:2698-2703.

Penterman, J., Abo, R. P., De Nisco, N. J., Arnold, M. F., Longhi, R., Zanda, M., and Walker, G. C. 2014. Host plant peptides elicit a transcriptional response to control the Sinorhizobium meliloti cell cycle during symbiosis. Proc. Natl. Acad. Sci. U.S.A. 111:3561-3566.

Pérez Guerra, J. C., Coussens, G., De Keyser, A., De Rycke, R., De Bodt, S., Van De Velde, W., Goormachtig, S., and Holsters, M. 2010. Comparison of developmental and stress-induced nodule senescence in Medicago truncatula. Plant Physiol. 152:1574-1584.

Pini, F., De Nisco, N. J., Ferri, L., Penterman, J., Fioravanti, A., Brilli, M., Mengoni, A., Bazzicalupo, M., Viollier, P. H., Walker, G. C., and Biondi, E. G. 2015. Cell cycle control by the master regulator CtrA in Sinorhizobium meliloti. PLoS Genet. 11:e1005232.

Pislariu, C. I., Murray, J. D., Wen, J., Cosson, V., Muni, R. R., Wang, M., Benedito, V. A., Andriankaja, A., Cheng, X., Jerez, I. T., Mondy, S., Zhang, S., Taylor, M. E., Tadege, M., Ratet, P., Mysore, K. S., Chen, R., and Udvardi, M. K. 2012. A Medicago truncatula tobacco retrotransposon insertion mutant collection with defects in nodule development and symbiotic nitrogen fixation. Plant Physiol. 159:1686-1699.

Plet, J., Wasson, A., Ariel, F., Le Signor, C., Baker, D., Mathesius, U., Crespi, M., and Frugier, F. 2011. MtCRE1-dependent cytokinin signaling integrates bacterial and plant cues to coordinate symbiotic nodule organogenesis in Medicago truncatula. Plant J. 65:622-633.

Pocard, J. A., Vincent, N., Boncompagni, E., Smith, L. T., Poggi, M. C., and Le Rudulier, D. 1997. Molecular characterization of the bet genes encoding glycine betaine synthesis in Sinorhizobium meliloti 102F34. Microbiology 143:1369-1379.

Price, P. A., Tanner, H. R., Dillon, B. A., Shabab, M., Walker, G. C., and Griffitts, J. S. 2015. Rhizobial peptidase HrrP cleaves host-encoded signaling peptides and mediates symbiotic compatibility. Proc. Natl. Acad. Sci. U.S.A. 112:15244-15249.

Reeve, W., Chain, P., O’Hara, G., Ardley, J., Nandesena, K., Bräu, L., Tiwari, R., Malfatti, S., Kiss, H., Lapidus, A., Copeland, A., Nolan, M., Land, M., Hauser, L., Chang, Y. J., Ivanova, N., Mavromatis, K., Markowitz, V., Kyrpides, N., Gollagher, M., Yates, R., Dilworth, M., and Howieson, J. 2010. Complete genome sequence of the Medicago microsymbiont Ensifer (Sinorhizobium) medicae strain WSM419. Stand. Genomic Sci. 2:77-86.

Rose, R. J. 2008. Medicago truncatula as a model for understanding plant interactions with other organisms, plant development and stress biology: past, present and future. Funct. Plant Biol. 35:253-264.

Roux, B., Rodde, N., Jardinaud, M. F., Timmers, T., Sauviac, L., Cottret, L., Carrère, S., Sallet, E., Courcelle, E., Moreau, S., Debellé, F., Capela, D., de Carvalho-Niebel, F., Gouzy, J., Bruand, C., and Gamas, P. 2014. An integrated analysis of plant and bacterial gene expression in symbiotic root nodules using laser-capture microdissection coupled to RNA sequencing. Plant J. 77:817-837.

Simsek, S., Ojanen-Reuhs, T., Stephens, S. B., and Reuhs, B. L. 2007. Strain-ecotype specificity in Sinorhizobium meliloti-Medicago truncatula symbiosis is correlated to succinoglycan oligosaccharide structure. J. Bacteriol. 189:7733-7740.

Starker, C. G., Parra-Colmenares, A. L., Smith, L., Mitra, R. M., and Long, S. R. 2006. Nitrogen fixation mutants of Medicago truncatula fail to support plant and bacterial symbiotic gene expression. Plant Physiol. 140:671-680.
Terpolilli, J. J., O’Hara, G. W., Tiwari, R. P., Dilworth, M. J., and Howieson, J. G. 2008. The model legume Medicago truncatula A17 is poorly matched for $\mathrm{N}_{2}$ fixation with the sequenced microsymbiont Sinorhizobium meliloti 1021. New Phytol. 179:62-66.

Truchet, G., Debellé, F., Vasse, J., Terzaghi, B., Garnerone, A. M., Rosenberg, C., Batut, J., Maillet, F., and Dénarié, J. 1985. Identification of a Rhizobium meliloti pSym2011 region controlling the host specificity of root hair curling and nodulation. J. Bacteriol. 164:1200-1210.

Van de Velde, W., Guerra, J. C., De Keyser, A., De Rycke, R., Rombauts, S., Maunoury, N., Mergaert, P., Kondorosi, E., Holsters, M., and Goormachtig, S. 2006. Aging in legume symbiosis. A molecular view on nodule senescence in Medicago truncatula. Plant Physiol. 141:711-720.

Van de Velde, W., Zehirov, G., Szatmari, A., Debreczeny, M., Ishihara, H., Kevei, Z., Farkas, A., Mikulass, K., Nagy, A., Tiricz, H., SatiatJeunemaître, B., Alunni, B., Bourge, M., Kucho, K., Abe, M., Kereszt, A., Maroti, G., Uchiumi, T., Kondorosi, E., and Mergaert, P. 2010. Plant peptides govern terminal differentiation of bacteria in symbiosis. Science 327:1122-1126.

Vanstraelen, M., Baloban, M., Da Ines, O., Cultrone, A., Lammens, T., Boudolf, V., Brown, S. C., De Veylder, L., Mergaert, P., and Kondorosi, E. 2009. APC/C-CCS52A complexes control meristem maintenance in the Arabidopsis root. Proc. Natl. Acad. Sci. U.S.A. 106:11806-11811.

Vasse, J., de Billy, F., Camut, S., and Truchet, G. 1990. Correlation between ultrastructural differentiation of bacteroids and nitrogen fixation in alfalfa nodules. J. Bacteriol. 172:4295-4306.

Vinardell, J. M., Fedorova, E., Cebolla, A., Kevei, Z., Horvath, G., Kelemen, Z., Tarayre, S., Roudier, F., Mergaert, P., Kondorosi, A., and Kondorosi, E. 2003. Endoreduplication mediated by the anaphasepromoting complex activator CCS52A is required for symbiotic cell differentiation in Medicago truncatula nodules. Plant Cell 15:20932105

Yoder, J. B., Briskine, R., Mudge, J., Farmer, A., Paape, T., Steele, K., Weiblen, G. D., Bharti, A. K., Zhou, P., May, G. D., Young, N. D., and Tiffin, P. 2013. Phylogenetic signal variation in the genomes of Medicago (Fabaceae). Syst. Biol. 62:424-438.

Young, N. D., Debellé, F., Oldroyd, G. E., Geurts, R., Cannon, S. B., Udvardi, M. K., Benedito, V. A., Mayer, K. F., Gouzy, J., Schoof, H., Van de Peer, Y., Proost, S., Cook, D. R., Meyers, B. C., Spannagl, M., Cheung, F., De Mita, S., Krishnakumar, V., Gundlach, H., Zhou, S., Mudge, J., Bharti, A. K., Murray, J. D., Naoumkina, M. A., Rosen, B., Silverstein, K. A., Tang, H., Rombauts, S., Zhao, P. X., Zhou, P., Barbe, V., Bardou, P., Bechner, M., Bellec, A., Berger, A., Bergès, H., Bidwell, S., Bisseling, T., Choisne, N., Couloux, A., Denny, R., Deshpande, S., Dai, X., Doyle, J. J., Dudez, A. M., Farmer, A. D., Fouteau, S., Franken, C., Gibelin, C., Gish, J., Goldstein, S., González, A. J., Green, P. J., Hallab, A., Hartog, M., Hua, A., Humphray, S. J., Jeong, D. H., Jing, Y., Jöcker, A., Kenton, S. M., Kim, D. J., Klee, K., Lai, H., Lang, C., Lin, S., Macmil, S. L., Magdelenat, G., Matthews, L., McCorrison, J., Monaghan, E. L., Mun, J. H., Najar, F. Z., Nicholson, C., Noirot, C., O’Bleness, M., Paule, C. R., Poulain, J., Prion, F., Qin, B., Qu, C., Retzel, E. F., Riddle, C., Sallet, E., Samain, S., Samson, N., Sanders, I., Saurat, O., Scarpelli, C., Schiex, T., Segurens, B., Severin, A. J., Sherrier, D. J., Shi, R., Sims, S., Singer, S. R., Sinharoy, S., Sterck, L., Viollet, A., Wang, B. B., Wang, K., Wang, M., Wang, X., Warfsmann, J., Weissenbach, J., White, D. D., White, J. D., Wiley, G. B., Wincker, P., Xing, Y., Yang, L., Yao, Z., Ying, F., Zhai, J., Zhou, L., Zuber, A., Dénarié, J., Dixon, R. A., May, G. D., Schwartz, D. C., Rogers, J., Quétier, F., Town, C. D., and Roe, B. A. 2011. The Medicago genome provides insight into the evolution of rhizobial symbioses. Nature 480 : $520-524$.

\section{AUTHOR-RECOMMENDED INTERNET RESOURCES}

GeNorm software: http://genorm.cmgg.be

The Medicago truncatula Hapmap Project database: http://www.medicagohapmap.org

Xlstat software: http://www.xlstat.com/ 